\title{
PENGARUH MOTIVASI, KOMPENSASI, DAN KEDISIPLINAN TERHADAP KINERJA KARYAWAN STUDY PADA PT PRIMA WIRANDI SIDOARJO
}

\author{
* Nanang Iswanto, Mahmudah Enny W, Siti Rosyafah \\ Prodi Manajemen Fakultas Ekonomi dan Bisnis Universitas Bhayangkara, Indonesia
}

DOI: 10.46821/benchmark.v1i1.21

\begin{abstract}
Abstrak
Penelitian ini bertujuan untuk mengetahui seberapa besar pengaruh variabel motivasi, kompensasi dan kedisiplinan terhadap kinerja karyawan pada PT Prima Wirandi. Teknik analisis data yang digunakan regresi linier berganda dengan menggunakan SPSS 20. Hasil didapatkan nilai adjusted R Square sebesar 82.3\%. Sehingga dapat dijelaskan bahwa $82.3 \%$ variabel motivasi, kompensasi, dan kedisiplinan mempengaruhi kinerja karyawan. Sedangkan selisihnya $17.7 \%$ dipengaruhi oleh variabel lain yang tidak ada dalam penelitian ini. Hasil penelitian ini menyimpulkan bahwasannya variabel motivasi dan kedisiplinan tidak memiiki pengaruh yang signifikan, kompensasi memiliki pengaruh yang signifikan terhadap kinerja karyawan pada PT Prima Wirandi. Variabel yang memiliki pengaruh dominan adalah Motivasi. Hasil penelitian ini memberikan implikasi bahwa faktor Motivasi, Kompensasi dan Kedisiplinan dapat mempengaruhi kinerja karyawan pada perusahaan.
\end{abstract}

Kata kunci : Motivasi, Kompensasi, Kedisiplinan dan Kinerja Karyawan

\begin{abstract}
This study aims to determine how much influence the variable motivation, compensation and discipline on employee performance at PT Prima Wirandi. Data analysis techniques used multiple linear regression using SPSS 20. The results obtained adjusted R Square value of $82.3 \%$. So that it can be explained that $82.3 \%$ of the variables of motivation, compensation, and discipline affect employee performance. While the difference of $17.7 \%$ is influenced by other variables not present in this study. The results of this study conclude that motivation and discipline variables have no significant effect, compensation has a significant effect on employee performance at PT Prima Wirandi. The variable that has the dominant influence is Motivation. The results of this study imply that Motivation, Compensation and Discipline factors can affect employee performance at the company
\end{abstract}

Keywords: Motivation, Compensation, Discipline and Employee Performance

\section{PENDAHULUAN}

\section{Latar Belakang Penelitian}

Pada era globalisasi pasar bebas sekarang ini perkembangan dunia usaha semakin ketat sehingga menimbulkan persaingan antar perusahaan untuk menjadi perusahaan yang unggul dan kompetitif sehingga dapat merebut pangsa pasar dari persaingan antar perusahaan tersebut. Dengan kondisi tersebut maka perusahaan di tuntut untuk memafaatkan kemampuan karyawan yang ada semaksimal mungkin. Oleh karena itu perusahaan harus memiliki menajemen yang baik sehingga dapat melihat dan 
menggunakan peluang - peluang yang ada serta dapat mengedentifikasi masalah dan menyeleksi serta mengimplementasikan dengan tepat. Menurut Mangkunegara (2012:5) "Manajemen sumber daya manusia didefinisikan sebagai suatu perencanaan pengorganisasian, pelaksanaan, dan pengawasan terhadap pengadaan, pengembangan, pemberian balas jasa, pengintegrasian, pemeliharaan, dan pemisahan tenaga kerja dalam rangka mencapai tujuan organisasi”.

PT. Prima Wirandi adalah sebuah perusahaan pengisian bahan bakar minyak yang bertempat di Jalan Raya Surabaya-Mojokerto KM.43. Sebagai perusahaan pengisian bahan bakar minyak (BBM) juga memerlukan manajemen sumber daya manusia yang baik guna tercapainya tujuan perusahaan, sehingga pihak-pihak yang terlibat aktivitas majemen perusahaan dituntut untuk meningkatkan kualitas sumber daya manusia dengan melihat peluang-peluang yang ada akan tetapi tetap efisien dan efektif dalam pembaiayaan atau pengeluaran.

Pada kondisi yang ditemui saat ini pada PT. Prima Wirandi dari hasil wawancara dari beberapa karyawan mengacu pada indikator - indikator Motivasi dalam hal kebutuhan rasa aman (Safety - need) masih dijumpai tidak adanya perlindungan perusahaan akan kecelakaan kerja, pengembangan karier karyawan, jaminan akan hari tua ketika mereka tidak lagi bekerja. Dan dalam hal kebutuhan sosial (Social-need) karyawan seperti program social/kebersamaan kurang diperhatikan oleh perusahaan sehinggal interaksi komunikasi, kekompakan dan juga rasa kekeluargaan/persahabatan antar karyawan kurang. Dan dalam hal kebutuhan penghargaan (Esteem-need) juga masih kurang bahkan tidak ada karena dari pimpinan/atasan kurang turun kebawahan/karyawan sehingga tidak ada pengakuan atau pujian secara langsung atas hasil kerja/kemampuan karyawan semua itu juga berdampak pada potensi - potensi yang ada pada karyawan berkurang karena perusahaan tidak dapat menjadi wadah/penampung akan pengembangan potensi-potensi karyawan padahal secara tidak langsung pengembangan itu perlu guna kemajuan perusahaan PT Prima Wirandi Sidoarjo. dari slip gaji karyawan masih dijumpai terjadinya ketidaksesuaian dalam pemberian bonus, insentif kepada karyawan atas usaha ekstra karyawan atas loyalitas atas keterampilan kinerjanya dan juga gaji yang diterima karyawan pun tidak sesuai dengan UMR yang berlaku. Juga dari hasil wawancara langsung dari beberapa karyawan dalam hal pembayaran terhadap bahaya (Hazard Protection) bentuk perlindungan asuransi kesehatan dan asuransi kecelakaan kerja juga tidak ada dalam perusahaan padahal hal tersebut sangat penting bagi karyawan khususnya operator karena bahaya uap bahan bakar minyak (BBM). pada PT. Prima Wirandi Sidoarjo juga masih dijumpai karyawan yang masih kurang dalam kedisiplinan, dilihat dari data kehadiran masih ada karyawan yang datang terlambat pulang lebih dahulu dan kurangnya kesadaran karyawan akan kedisiplinan akan aturan perusahaan dilihat dari adanya sebagian karyawan yang keluar masuk pada jam kerja.

Berdasarkan latar belakang dan permasalahan yang sudah diuraikan pada PT. Prima Wirandi, maka peneliti tertarik untuk melakukan penelitian dengan mengambil judul "PENGARUH MOTIVASI, KOMPENSASI, DAN KEDISIPLINAN TERHADAP KINERJA KARYAWAN PADA PT. PRIMA WIRANDI SIDOARJO". 
METODE PENELITIAN

Kerangka Proses Berpikir

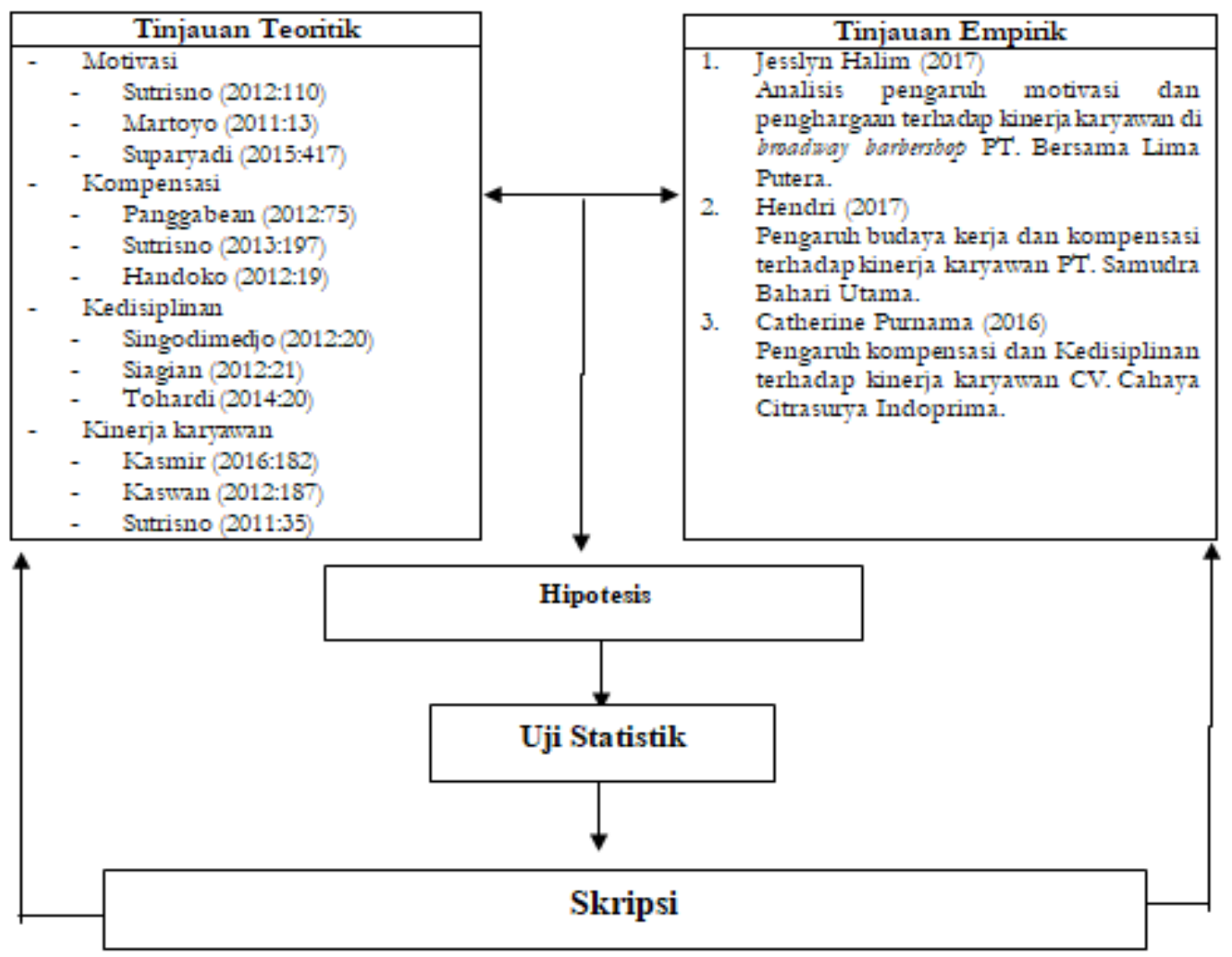

Sumber: Peneliti (2018)

\section{Gambar 2. Kerangka Proses Berpikir}

\section{Target Penelitian}

Adapun yang menjadi populasi penelitian ini adalah semua karyawan PT. Prima Wirandi sebanyak 70 orang. jumlah sampel yang digunakan dalam penelitian ini adalah 70 responden. Jumlah ini merupakan jumlah dari seluruh karyawan (sensus) PT. Prima Wirandi.

\section{Teknik pengumpulan data}

Teknik pengumpilan data dalm pnelitian ini menggunakan Kuesioner. Kuesioner merupakan teknik pengumpulan data yang dilakukan dengan cara memberi seperangkat pertanyaan atau pernyataan tertulis kepada responden untuk dijawab. Serta merupakan teknik pengumpulan data yang efisien bila peneliti tahu dengan pasti variabel yang akan diukur dan tahu apa yang diharapkan dari responden. Kuesioner juga cocok digunakan jika jumlah responden cukup besar dan tersebar diwilayah yang luas. 
Teknik Analisis Data

Analisa yang akan digunakan dalam penelitian ini adalah analisa deskriptif, uji validitas, uji realibilitas, analisa regresi linear berganda, uji $\mathrm{F}$, uji t yang kemudian diolah menggunakan SPSS (Statistical Product and Service Solution) 20.0 for windows.

\section{HASIL ANALISIS DAN PEMBAHASAN}

\section{Uji Validitas}

indikator-indikator tiap variabel yang digunakan dalam penelitian ini semuanya memiliki nilai korelasi diatas rtabel sebesar 0,2352, Hal ini menunjukan bahwa semua indikator yang digunakan untuk mengukur semua variabel dalam penelitian ini dinyatakan mempunyai validitas yang tinggi.

\section{Uji Reliabilitas}

Variabel bebas yang terdiri dari Motivasi (X1), Kompensasi (X2), Kedisiplinan (X3), serta variabel terikat Kinerja Karyawan (Y) masing-masing memiliki nilai Alpha Cronbach yang lebih besar dari 0,6. Hal ini menunjukkan bahwa semua variabel tersebut adalah reliabel dan dapat digunakan pada analisis selanjutnya.

\section{Analisis Regresi Linier Berganda}

Untuk mengetahui seberapa kuat hubungan ketiga variabel bebas tersebut terhadap variabel terikat dapat dilihat pada koefisien korelasi $(\mathrm{R})$ dan untuk mengetahui seberapa besar pengaruh variabel bebas terhadap variabel terikat dapat dilihat pada nilai koefisien determinasi ( $R$ square atau R2) yang ditunjukkan pada tabel 2.

Hasil analisis regresi berganda pada Tabel 2 didapatkan nilai koefisien korelasi berganda (R) sebesar 0,823. Hal ini menunjukkan bahwa antar variabel bebas dan variabel terikat mempunyai tingkat hubungan dalam kategori Sangat Kuat. Adapun nilai koefisien determinasi (R2) didapatkan sebesar 0,823 atau 82,3\%. Artinya bahwa variabel bebas mempunyai pengaruh terhadap variabel terikat sebesar $82,3 \%$, sedangkan sisanya sebesar $17,7 \%$ dipengaruhi oleh faktor lain yang tidak termasuk dalam variabel penelitian ini.

\section{Tabel 1}

Hasil Uji Reliabilitas

\begin{tabular}{ccc}
\hline Variabel & Nilai Alpha & Keterangan \\
\hline Motivasi (X1) & 0.801 & Reliabel \\
Kompensasi (X2) & 0.793 & Reliabel \\
Kedisiplinan (X3) & 0.798 & Reliabel \\
Kinerja Karyawan (Y) & 0.647 & Reliabel \\
\hline
\end{tabular}

Sumber: Peneliti (2019)

\section{Tabel 2}

Koefisien Korelasi dan Determinasi

\begin{tabular}{lllll}
\hline Model & $\mathrm{R}$ & $\mathrm{R}$ Square & Adjusted R & Std. Error of the Estimate \\
\hline 1 & .823 & .677 & .663 & 1.49665 \\
\hline
\end{tabular}

Sumber: Peneliti (2019) 
Hasil Pengujian model secara bersama-sama (simultan) di atas diperoleh nilai Fhitung sebesar 45,648, Nilai ini lebih besar dari pada Ftabel sebesar 2,51, Demikian juga dengan nilai signifikan yang dihasilkan sebesar 0,000 yang lebih kecil dari nilai signifikan yang digunakan yaitu $\alpha=5 \%$ atau 0,05, Sehingga dapat disimpulkan bahwa H0 ditolak dan $\mathrm{Ha}$ diterima. Artinya bahwa variabel Motivasi (X1), Kompensasi (X2), dan Kedisiplinan (X3) secara simultan (bersama-sama) memiliki pengaruh yang signifikan terhadap Kinerja Karyawan (Y) pada PT. Prima Wirandi.

\section{Uji Parsial (Uji t)}

Dari hasil perhitungan didapatkan nilai thitung sebesar 1,813 dan nilai signifikasi sebesar 0,074 dengan tingkat signifikansi sebesar 0,05 . Oleh karena itu nilai thitung $(1,813)>$ ttabel $(1,66827)$ dan nilai signifikansi yang dihasilkan sebesar 0,074 yang lebih besar dari 0,05, H0 diterima dan Ha ditolak artinya bahwa variabel Motivasi (X1) secara parsial tidak memiliki pengaruh yang signifikan terhadap Kinerja Karyawan (Y).

Dari hasil perhitungan didapatkan nilai thitung sebesar 1,891 dan nilai signifikasi sebesar 0,036 dengan tingkat signifikansi sebesar 0,05. Oleh karena itu nilai thitung $(1,891)>$ ttabel $(1,66827)$ dan nilai signifikansi yang dihasilkan sebesar 0,036 yang lebih kecil dari 0,05, H0 ditolak dan Ha diterima artinya bahwa variabel Kompensasi (X2) secara parsial memiliki pengaruh yang signifikan terhadap Kinerja Karyawan (Y).

Dari hasil perhitungan didapatkan nilai thitung sebesar 1,501 dan nilai signifikasi sebesar 0,138 dengan tingkat signifikansi sebesar 0,05. Oleh karena itu nilai thitung $(1,501)<$ ttabel $(1,66827)$ dan nilai signifikansi yang dihasilkan sebesar 0,138 yang lebih besar dari 0,05, H0 diterima dan Ha ditolak artinya bahwa variabel Kedisiplinan (X3) secara parsial tidak memiliki pengaruh yang signifikan terhadap Kinerja Karyawan (Y).

\section{Variabel yang berpengaruh Dominan terhadap Kinerja karyawan (Y)}

Dari ketiga variabel bebas yang terdiri dari Motivasi (X1), Kompensasi (X2) dan Kedisiplinan (X3) dapat diketahui bahwa variabel Motivasi (X1) yang mempunyai nilai koefisien $\beta$ (beta) terbesar yaitu sebesar 0,353 diantara variabel bebas-bebas yang lain, sehingga dapat disimpulkan bahwa variabel bebas yang mempunyai pengaruh dominan terhadap variabel terikat Kinerja Karyawan (Y) adalah Motivasi (X1).

Tabel 3

Uji Pengaruh Simultan (Uji F) ANOVA

\begin{tabular}{rrrrrrr}
\hline & Model & Sum of Squares & Df & Mean Square & F & Significance \\
\hline \multirow{2}{*}{1} & Regression & 306.748 & 3 & 102.249 & 45.648 &, $000^{\mathrm{b}}$ \\
& Residual & 147.837 & 66 & 2.240 & & \\
& Total & 454.586 & 69 & & & \\
\hline
\end{tabular}

Sumber: Peneliti (2019) 
Tabel 4

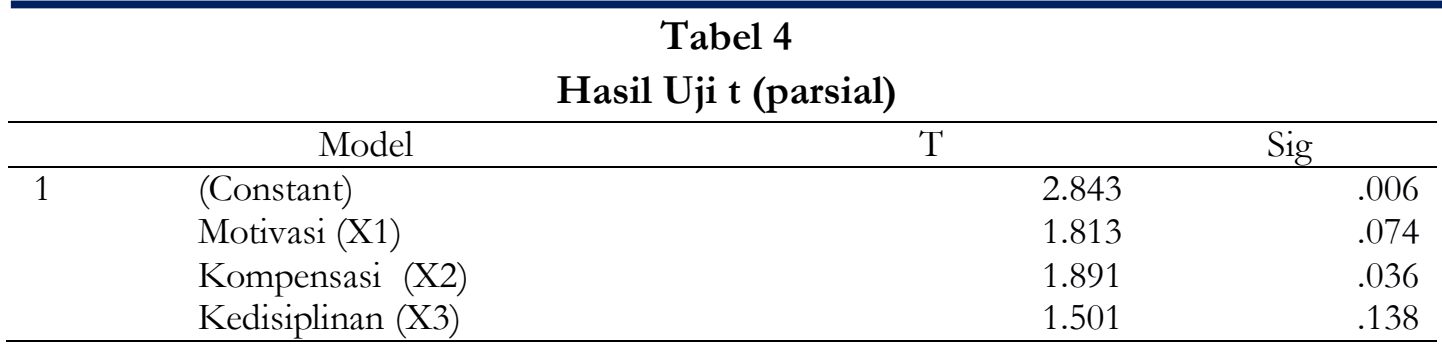

Sumber: Peneliti (2019)

Tabel 5

Variabel Yang Berpengaruh Dominan

\begin{tabular}{llcc}
\hline & & \multicolumn{2}{c}{ Standardized Coefficients } \\
\cline { 3 - 4 } & & Beta & \\
\hline 1 & (Constant) & & .353 \\
& Motivasi (X1) & & .233 \\
& Kompensasi (X2) & & .278 \\
& Kedisiplinan (X3) & & \\
\hline
\end{tabular}

Sumber: Peneliti (2019)

\section{SIMPULAN}

Dari hasil analisis perhitungan tersebut diatas didapatkan hasil Bahwa variabel bebas Kompensasi (X2) secara parsial memiliki pengaruh yang signifikan terhadap Kinerja Karyawan (Y) study pada PT. Prima Wirandi. Sedangkan Variabel Motivasi (X1) dan Kedisiplinan (X3) secara Parsial tidak memiliki pengaruh yang signifikan terhadap Kinerja Karyawan (Y). Hasil Pengujian bahwa variabel Motivasi (X1), Kompensasi (X2), dan Kedisiplinan (X3) secara simultan (bersama-sama) memiliki pengaruh yang signifikan terhadap Kinerja Karyawan (Y) pada PT. Prima Wirandi. dengan diperoleh nilai Fhitung sebesar 45,648, Nilai ini lebih besar dari pada Ftabel sebesar 2,51, Demikian juga dengan nilai signifikan yang dihasilkan sebesar 0,000 yang lebih kecil dari nilai signifikan yang digunakan yaitu $\alpha=5 \%$. atau 0,05 . Berdasarkan hasil pengujian bahwa variabel bebas Motivasi (X1) yang mempunyai pengaruh dominan terhadap variabel terikat Kinerja karyawan (Y) yang mempunyai nilai koefisien $\beta$ (beta) terbesar yaitu sebesar 0,353 diantara variabel Kompensasi dan Kedisiplinan, sehingga sesuai dengan hipotesis yang ketiga "Bahwa Motivasi berpengaruh secara dominan terhadap Kinerja pada karyawan PT. Prima Wirandi Sidoarjo. Bagi Perusahaan, agar karyawan PT. Prima Wirandi memiliki Kinerja Karyawan yang tinggi maka perusahaan harus mampu meningkatkan Motivasi kepada karyawan dengan memenuhi kebutuhan Fisiologis, kebutuhan rasa aman pengembangan karier karyawan serta jaminan hari tua karyawan, kebutuhan sosial, kebutuhan penghargaan dengan diakui kemampuan dan keahlian karyawan dan kebutuhan aktualisasi diri dengan proses pengembangan potensi yang dimiliki karyawan sehingga perusahaan harus bisa menjadi wadah dan pendukung untuk pengembangan potensi/kemampuan karyawan. Agar karyawan PT. Prima wirandi memiliki Kinerja Karyawan yang tinggi dan cenderung meningkat maka perusahaan harus mampu memberikan Kompensasi dengan adil kepada karyawan dengan memberikan gaji yang sesuai dengan aturan atau UMR yang berlaku, memberikan insentif dan bonus, mampu membayar terhadap bahaya sebagai bentuk perlindungan kerja berupa asuransi kesehatan dan asuransi kecelakaan kerja. Agar karyawan PT. Prima Wirandi memiliki Kinerja 
Karyawan yang tinggi dan cenderung meningkat maka pemimpin/atasan harus mampu memberikan teladan dan panutan oleh para karyawan dengan teladan pemimpin yang baik, dalam memberikan tugas atau pekerjaan harus jelas dan ideal sesuai kemampuan karyawan yang bersangkutan sehingga bisa efektif dan optimal dalam hasil, perusahaan harus mampu memberikan kesejahteraan kepada karyawan sebagai balas jasa sehingga kedisiplinan mereka akan semakin baik pula, pengawasan melekat secara langung dari pemimpin/atasan kepada karyawan juga dapat mewujudkan kedisiplinan yang meningkat. Bagi Karyawan, sebagai karyawan pemberian Kompensasi berupa gaji, upah, insentif dan bonus dan kebutuhan lain yang diberikan perusahaan dan untuk menunjang kinerja karyawan merupakan hal yang mutlak yang harus di berikan oleh perusahaan akan tetapi kontribusi kinerja karyawan akan perusahaan juga harus di tingkatkan sehingga dapat meningkatkan dan memajukan perusahaan bukan hanya salah satu yang di untungkan perusahaan atau karyawan tetapi juga harus sama-sama menguntungkan atau sejalan dengn baik sehingga kesejahteraan keduanya akan terwujud. Tanggung jawab karyawan dan kedisiplinan karyawan merupakan tolak ukur dalam memberikan Kompensasi. Bagi Peneliti Selanjutnya. Bagi peneliti selanjutnya hendaknya penelitian lebih lanjut dapat menambahkan variabel lain yang dapat mempengaruhi Kinerja Karyawan. Sehingga dapat menjadikan penelitian yang lebih luas dan hasil yang lebih maksimal.

\section{DAFTAR PUSTAKA}

Anwar Prabu Mangkunegara, AA (.2012). Manajemen Sumber Daya Manusia Perusahaan,.Remaja Rosdakarya, Bandung.

Ardana, Sofyandi (2016). Manajemen Sumber Daya Manusia. Graha Ilmu, Yogyakarta.

Davis, Keith dan Newstrom (2014). Perilaku Dalam Organisasi, Edisi ketujuh, Penerbit Erlangga, Jakarta.

Ghozali, Imam. (2014). Aplikasi Analisis Multivariate dengan program IBM SPSS 19, Edisi kelima, Universitas Diponegoro, Semarang.

Halim, Jesslyn. (2017). Metode Penelitian Manajemen Pedoman Untuk Penulisan Skripsi, Tesis, dan Disertasi, Edisi Lima, Badan Penerbit Universitas Diponegoro, Semarang.

Hendri. (2017). Pengaruh budaya kerja dan kompensasi terhadap kinerja karyawan PT. Samudra Bahari Utama, Skripsi, Universitas Kristen Petra, Surabaya.

Kamil, E.p. (2012). Analisis pengaruh motivasi dan penghargaan terhadap kinerja karyawan di broadway barbershop PT. Bersama Lima Putera. Skripsi, Universitas Kristen Petra, Surabaya.

Purnama, Catherine (2016). Pengaruh kompensasi dan Kedisiplinan terhadap kinerja karyawan CV. Cahaya Citrasurya Indoprima, Skripsi, Universitas Kristen Petra, Surabaya.

Priyatno, D. (2013). Teknik Mudah dan Cepat Melakukan Analisa Data Penelitian dengan SPSS. Gava Media, Yogyakarta.

Robbins, Stephen P, and Coulter, Mary. (2012). Management, Pearson Education, Inc, New Jersey.

Stephen P.Robbins. (2010). Perilaku Organisasi Buku 2, Salemba, Empat, Jakarta. 
Sugiyono. (2012), Metode Penelitian Kuantitatif Kualitatif dan R \& D, Cetakan keenam belas, Alfabeta, Bandung.

Sugiyono.( 2013, Metodeologi Penelitian Kuantitatif, Kualitatif Dan RひD, Alfabeta, Bandung.

Sugiyono. (2014). Metode Penelitian Pendidikan Pendekatan Kuantitatif, Kualitatif Dan R\&D. Alfabeta, Bandung.

Supomo, R .(2018). Manajemen Sumber Daya Manusia. Cetakan satu, Yrama Widya, Bandung.

Wibowo. (2013). Perilaku dalam Organisasi. Raja Grafindo Persada. Jakarta. 